\title{
Effects of short-term caloric restriction on circulating free IGF-I, acid-labile subunit, IGF-binding proteins (IGFBPs)-1-4, and IGFBPs-1-3 protease activity in obese subjects
}

\author{
Michael Højby Rasmussen, Anders Juul ${ }^{1}$, Lise Lund Kjems and Jannik Hilsted \\ Department of Endocrinology, Hvidovre Hospital, University of Copenhagen, DK-2650 Copenhagen, Denmark and ${ }^{1}$ Department of Growth and
} Reproduction, Rigshospitalet, University of Copenhagen, DK-2200 Copenhagen, Denmark

(Correspondence should be addressed to M H Rasmussen who is now at Langs Hegnet 52 B, Kongens Lyngby DK-2800, Denmark;

Email:mhr@dadlnet.dk)

\begin{abstract}
Objective: Decreased levels of GH and total IGF-I have been reported in obesity. It has been hypothesized that increased free (biologically active) IGF-I levels generated from IGF-binding protein (IGFBP) protease activity could be the mechanism for the low GH release in dieting obese subjects. However, no published data exist on free IGF-I levels, acid labile subunit (ALS), or IGFBP protease activity in relation to GH release during a hypocaloric diet. The main purpose of this study was to determine free IGF-I, ALS, IGFBPs-1-4, and IGFBPs-1-3 protease activity in relation to 24-h GH release before and after a short-term very low-calorie diet (VLCD).

Design: Six obese subjects before weight loss, five after an average weight loss of $36.1 \mathrm{~kg}$, and five ageand sex-matched lean controls underwent a 4-day VLCD. All subjects were studied on two occasions, once during normal basic diet and again during the last day of the VLCD (1.6 MJ).

Methods: Free IGF-I was determined by a non-competitive immunoradiometric assay.

Results: Free IGF-I levels decreased in concert with increased ALS and unchanged blunted GH release after a VLCD in the obese subjects. IGFBPs-1-3 proteolytic activity was found to be unchanged by hypocaloric diet in all groups.

Conclusions: We conclude that free IGF-I decreases after a short-term hypocaloric diet in obese subjects with no concomitant change in 24-h GH release. Circulating free IGF-I per se cannot be the main mechanism of the attenuated GH release in dieting obese subjects.
\end{abstract}

European Journal of Endocrinology 155 575-581

\section{Introduction}

In obesity, spontaneous growth hormone (GH) secretion is decreased $(1,2)$ compared with normalweight subjects $(2,3)$, total insulin-like growth factor-I (IGF-I) is low (1-3), whereas reports on free IGF-I are not unanimous (4-6). We have been previously demonstrated that short-term caloric restriction had no impact on the 24-h GH release in obese subjects in contrast to that observed in the lean subjects (7); this observation has later been confirmed by other researchers (8). It has been hypothesized that the lack of stimulation of $\mathrm{GH}$ release by caloric restriction in obese subjects could be due to a relatively enhanced bioavailability of IGFI $(7,8)$ generated from low IGF-binding protein (IGFBP)-1 levels and IGFBP proteolysis. It is believed that the bioactivity of IGF-I is maintained primarily through free IGF-I and therefore might be a critical component in the feedback regulation of $\mathrm{GH}$ secretion and the bioactivity on target tissue (9).
However, no data have been previously reported on free IGF-I levels and GH release during short-term caloric restriction in obese subjects before and after, diet-induced weight loss.

IGFBP proteolysis is believed to be a general mechanism increasing IGF bioavailability and biological activity in the presence of IGFBPs and acid-labile subunit (ALS) and thereby regulating IGF release in serum (10). Furthermore, insulin resistance has been suggested to play a part in IGFBP-3 proteolysis (11). Thus, increased IGFBP proteolysis could enhance IGFI bioavailability to its target tissues, which in turn could be a potential beneficial adaptive response to compensate for the $\mathrm{GH}$ hyposecretion in obesity. Therefore, both IGFBP proteolysis and ALS are important in understanding the physiology of the IGF system and pathophysiologic metabolic conditions such as obesity. No studies published so far have reported on IGFBPs-1, -2 and -3 proteolytic activity, and ALS in relation to the GH-IGF-I axis in obese subjects during caloric restriction. 
Leptin associated with hyperinsulinemia (3), has an inverse relationship with IGFBP-1 $(12,13)$ and a blunted response to short-term fasting in obesity (8). However, whether the leptin responses in obese subjects, and obese subjects after weight loss are altered in concert with GH release during short-term hypocaloric diet is not known.

The aim of our study was to explore the effect of a short-term very low-calorie diet (VLCD) on the response of free IGF-I, ALS, IGFBPs-1-3 protease activity, IGFBPs1-4, leptin, and 24-h GH release in obese subjects, obese subjects after weight loss and lean control subjects.

\section{Subjects and methods}

\section{Subjects}

Three groups of subjects were studied: six obese subjects before weight loss, five after weight loss (average weight loss, $36.1 \pm 7.5 \mathrm{~kg}$ ), and five age- and sex-matched healthy normal weight control subjects (Table 1). All the subjects gave informed consent. The revised Helsinki 2 Declaration was observed, and the study was approved by the Copenhagen Municipal Ethical Committee.

\section{Weight loss study}

The obese subjects participated in a structured, outpatient weight-loss program where the goal was to achieve ideal body weight. During the initial phase, the subjects consumed a commercial VLCD (Oluf Mørk Biochemie Ltd, Copenhagen, Denmark) that provided 1.6 MJ energy/day. The subjects visited the outpatient clinic weekly for body weight measurements and nutrition counseling. When the body weight decreased to approximately $130 \%$ of ideal body weight, the patients were instructed to discontinue the $1.6 \mathrm{MJ}$ energy/day diet and begin consuming 5.0 MJ/day diet of normal food items; by doing so, the patients used the diet and nutrition materials that had been supplied to them and discussed during the nutrition counseling sessions. When ideal body weight was achieved or no further weight could be lost, the patients were instructed to consume a basic $8.0 \mathrm{MJ} /$ day diet $(15 \%$ of energy from protein, 55\% from carbohydrate, and 30\%

Table 1 Body mass index (BMI), weight, gender, and age in lean, obese, and obese subjects after weight loss.

\begin{tabular}{lccc}
\hline & $\begin{array}{c}\text { Lean controls } \\
(n=5)\end{array}$ & $\begin{array}{c}\text { Obese } \\
(n=6)\end{array}$ & $\begin{array}{c}\text { Obese after } \\
\text { weight loss } \\
(n=5)\end{array}$ \\
\hline $\mathrm{BMl}\left(\mathrm{kg} / \mathrm{m}^{2}\right)$ & $22.9 \pm 0.6$ & $39.5 \pm 1.7$ & $28.5 \pm 2.1$ \\
$\begin{array}{l}\text { Weight }(\mathrm{kg}) \\
\begin{array}{l}\text { Gender } \\
(\mathrm{female} / \text { male) }\end{array}\end{array}$ & $\begin{array}{c}67.9 \pm 1.5 \\
4 / 1\end{array}$ & $\begin{array}{c}112.3 \pm 8.2 \\
5 / 1\end{array}$ & $\begin{array}{c}85.6 \pm 9.6 \\
4 / 1\end{array}$ \\
Age & $29.4 \pm 1.2$ & $30.8 \pm 3.1$ & $28.0 \pm 3.7$ \\
\hline
\end{tabular}

from fat), which was individually adjusted for each patient to obtain energy balance. Energy intake was further adjusted down or up for each subject on a weekly basis (during weekly dietary counseling sessions) to reach a final, and stable body weight (e.g. if the body weight began to increase then the daily energy intake was reduced). The obese subjects after weight loss were kept at the test weight for a minimum of 1 month before the experiments.

\section{Short-term hypocaloric diet design}

The effect of 4 days of hypocaloric diet on circulating free IGF-I, IGFBPs-1-4, ALS, IGFBPs-1-3 protease, leptin, and 24-h GH release activity were studied in all subjects. All subjects were studied on two occasions, once during a normal $8.0 \mathrm{MJ} /$ day basic diet supplemented with calories ad libitum and again during the last 24-h of a 96-h VLCD (1.6 MJ/day). Adherence to the diet was confirmed by a marked increase in urinary excretion of ketone bodies $(>10 \mathrm{mmol} / \mathrm{l})$.

\section{4-h experimental deign}

All subjects were admitted to the metabolic ward at 0730 h. A cannula (Viggo AB, Vingmed, Denmark) was placed in a forearm vein. Blood withdrawal commenced $30 \mathrm{~min}$ after venipuncture through a non-thrombogenic catheter (Carmeda; Viggo AB) inserted through the cannula and connected to an automatic constant withdrawal pump. The withdrawal rate was $3.5 \mathrm{ml} / \mathrm{h}$, and the reservoir tubes were changed at 20-min intervals over the following 24-h period. Subjects were allowed normal physical activity and not permitted to nap or sleep until $2230 \mathrm{~h}$. The fasting blood samples were taken after the subjects had fasted overnight. After collection, the samples were immediately centrifuged at $4{ }^{\circ} \mathrm{C}$ for $20 \mathrm{~min}$ and the resulting serum samples were immediately frozen.

\section{Assays}

Free IGF-I was determined by a commercially available non-competitive IRMA (Diagnostic Systems Laboratories, Inc., Webster, TX, USA). Detection limit of dissociable free IGF-I was $0.03 \mu \mathrm{g} / \mathrm{l}$. Intra- and inter-assay variations were 3.3 and $10.7 \%$ respectively. Plasma glucose was measured using an automated glucose oxidase method (Glucose Analyzer II; Beckmann Instruments, Fullerton, CA, USA). Insulin was measured using an RIA method as described previously (1). Leptin was measured using a double-antibody RIA with rabbit anti-human leptin antibodies, ${ }^{125}$ I-labeled human leptin as tracer, and human leptin as standard (Linco Res., St Louis, MO, USA). The IGFBP protease assays were performed as described previously using recombinant human IGFBPs (rhIGFBP) (14). The ${ }^{125}$ I-IGFBP-3 was obtained from 
Diagnostic System Laboratories, while iodination of rhIGFBP-1 (obtained from UBI, Lake Placid, NY, USA) and rhIGFBP-2 (obtained from Sandoz Pharma Ltd, Basel, Switzerland) was performed in Prof Allan Flyvbjerg's laboratory by the cloramine-T method. ${ }^{125}$ I-IGFBPs- $1,-2$ or -3 (30 000 c.p.m.) were incubated for $18 \mathrm{~h}$ at $37^{\circ} \mathrm{C}$ with $2 \mu \mathrm{l}$ serum samples from the obese and normal weight subjects and subjected to SDS-PAGE as described earlier. On each gel, internal control sera from normal controls (in the IGFBPs-1-3 protease assays) and termpregnant woman (in the IGFBP-3 protease assay), or seminal plasma (in the IGFBP-1 and IGFBP-2 protease assays) were applied. Electrophoresed gels were fixed in a solution of $7 \%$ acetic acid, dried, and autoradiographed. The degree of proteolysis for each sample was given as the percentage of proteolytic cleavage products for each lane. Serum IGFBPs-1, -2, -3, and 4 were analyzed by western ligand blotting (WLB). WLB, SDS-PAGE, and ligand-blot analysis were performed in serum from all subjects according to the method of Hossenlopp et al. (15). Autoradiograms of IGFBP protease and WLB assays were quantified by densitometry using a Shimadzu CS9001 PC dual-wavelength flying spot scanner.

The relative density of the bands was measured as arbitrary absorbency units per square millimeter $\left(\mathrm{AU} / \mathrm{mm}^{2}\right)$. ALS was determined by a commercially available ELISA (Diagnostic Systems Laboratories, Inc.) (16). The serum GH concentration was determined using an immunofluorometric assay (trIFMA, Delfia; Wallac, Turku, Finland), as described previously (1). The detection limit of the hGH assay was $0.01 \mu \mathrm{g} / \mathrm{l}$.

\section{Calculations}

The secretory 24-h GH release was analyzed using the Pulsar program developed by Meriam and Watcher (17) and calculations were performed on a desk-top IBM-PC compatible computer with a PC-adapted Pulsar program as described previously (1). The area under the curve was estimated above the calculated baseline. Of the $2304 \mathrm{GH}$ measurements, 15 were below the assay detection limit and were not assigned values in the Pulsar program. The homeostasis model assessment (HOMA) has been described previously by Matthews and co-workers (18) and assessment of the fasting glucose and insulin concentrations in each subject allows the evaluation of insulin sensitivity using the HOMA-continuous infusion of glucose with model assessment Calculator Program (19).

\section{Anthropometric procedures}

Body mass index was calculated as weight $(\mathrm{kg}) /$ height $\left(\mathrm{m}^{2}\right)$. Body weight was measured to the nearest $0.1 \mathrm{~kg}$ with the use of an electronic scale (Seca 070; Seca, Copenhagen, Denmark).

\section{Statistics}

Results are expressed as mean \pm s.E.M. Student's unpaired $t$-test was used to compare the significance of differences between groups and Student's paired $t$-test was used to assess changes within the same group. The level of statistical significance was set at $P<0.05$. No sample size calculation was made for this exploratory study. Three groups of subjects were studied: six obese subjects before weight loss, five after weight loss, and five age- and sex-matched healthy normal weight control subjects. It was anticipated that a small number of subjects in each group were sufficient to detect major changes within groups in the explored parameters during a VLCD.

\section{Results}

\section{Body weight}

In the three groups undergoing the 4-day hypocaloric study, the VLCD induced a mean weight loss of $2.2 \mathrm{~kg}$ (range 1.6-3.0 kg) in the lean subjects, $3.0 \mathrm{~kg}$ (range 1.8-4.3) in the obese subjects, and $2.6 \mathrm{~kg}$ (range 1.5$3.7 \mathrm{~kg}$ ) in the obese subjects after weight loss. Adherence to the diet was well tolerated. One of the obese subjects who underwent the examinations before and during VLCD dropped out during the weight-loss study due to lack of motivation and it was therefore not possible to include them in the re-examination after weight loss. Urinary ketone body excretion was detectable in all subjects and did not differ between groups during VLCD.

\section{4-h GH release}

The 24-h GH release was decreased in obese subjects compared with lean subjects, whereas no difference was found in the 24-h GH release between obese subjects after weight loss and lean subjects (Table 2). An increase in 24-h GH release occurred in the normal subjects during VLCD, whereas no change occurred in the obese subjects (Fig. 1, Table 2). The 24-h GH release data have been reported in detail separately (7).

\section{Free IGF-I, IGFBPS-1-4, ALS and IGFBPs-1-3 proteolyse}

Free IGF-I levels were similar in obese subjects, lean and obese subjects after weight loss, and a decrease occurred during VLCD in the obese subjects, whereas no significant decrease was present in the lean subjects and obese subjects after weight loss (Fig. 2, Table 2). 
Table 2 Free insulin-like growth factor-I (IGF-I), 24-h growth hormone (GH), IGF-binding proteins (IGFBP) 1-4, acid labile subunit (ALS), IGFBPs-1-3 proteolytic activity, leptin and homeostasis model assessment (HOMA) in lean subjects, obese subjects, and obese subjects after weight loss, before and after 4 days on a very low-calorie diet (VLCD).

\begin{tabular}{|c|c|c|c|c|c|c|}
\hline & Lean & Lean VLCD & Obese & Obese VLCD & $\begin{array}{l}\text { Obese after } \\
\text { weight loss }\end{array}$ & $\begin{array}{l}\text { Obese after } \\
\text { weight loss } \\
\text { VLCD }\end{array}$ \\
\hline Free IGF-I $(\mu \mathrm{g} / \mathrm{I})$ & $4.0 \pm 0.1$ & $2.8 \pm 0.6$ & $3.1 \pm 0.7$ & $1.6 \pm 0.2^{*}$ & $3.7 \pm 1.2$ & $2.8 \pm 0.8$ \\
\hline AUC GH $((\mu \mathrm{g} / \mathrm{l}) \times 24 \mathrm{~h})$ & $97 \pm 23$ & $129 \pm 55^{\star}$ & $38 \pm 14^{\dagger}$ & $31 \pm 9^{\ddagger}$ & $65 \pm 29$ & $132 \pm 51$ \\
\hline IGFBP-1 AU (mm²) & $3.3 \pm 0.5$ & $7.3 \pm 1.6^{*}$ & $3.4 \pm 0.4$ & $3.1 \pm 0.3^{\dagger}$ & $2.8 \pm 0.5$ & $4.2 \pm 2.5$ \\
\hline IGFBP-2 AU (mm²) & $9.1+1.8$ & $7.7+2.0$ & $4.0+0.7^{\dagger}$ & $5.9+1.3^{*}$ & $10.5+4.5$ & $8.5+2.1$ \\
\hline IGFBP-3 AU ( $\left.\mathrm{mm}^{2}\right)$ & $249 \pm 34$ & $187 \pm 22^{*}$ & $260 \pm 53$ & $255 \pm 36$ & $245 \pm 12$ & $195 \pm 12^{*}$ \\
\hline IGFBP-4 AU (mm²) & $4.0 \pm 0.5$ & $2.7 \pm 0.4$ & $5.3 \pm 1.4$ & $4.8 \pm 1.7$ & $4.9 \pm 0.7$ & $3.3 \pm 1.8$ \\
\hline ALS $(\mu \mathrm{g} / \mathrm{l})$ & $20.4 \pm 1.3$ & $23.3 \pm 1.7$ & $26.2 \pm 2.7$ & $30.1 \pm 3.2^{*}$ & $18.6 \pm 3.1$ & $20.9 \pm 3.3$ \\
\hline IGFBP-1 proteolysis (\%) & $15.3 \pm 2.8$ & $15.2 \pm 3.5$ & $15.8 \pm 1.9$ & $14.1 \pm 1.9$ & $15.0 \pm 1.6$ & $17.7 \pm 2.6$ \\
\hline IGFBP-2 proteolysis (\%) & $10.9 \pm 1.2$ & $12.2 \pm 1.1$ & $14.7 \pm 1.2$ & $12.6 \pm 1.1$ & $10.7 \pm 1.2$ & $12.8 \pm 2.0$ \\
\hline IGFBP-3 proteolysis (\%) & $15.3 \pm 2.7$ & $14.35 \pm 2.4$ & $15.9 \pm 2.6$ & $17.7 \pm 2.4$ & $15.1 \pm 1.8$ & $17.9 \pm 1.8$ \\
\hline Leptin (ng/ml) & $7.2 \pm 2.0$ & $2.6 \pm 0.7^{*}$ & $30.0 \pm 3.5^{\dagger}$ & $25.1 \pm 4.4^{\dagger}$ & $12.0 \pm 5.1$ & $6.4 \pm 2.6^{*}$ \\
\hline HOMA-S (\%) & $169 \pm 18$ & & $77 \pm 9^{\ddagger}$ & & $166 \pm 32$ & \\
\hline
\end{tabular}

AUC, area under the curve. ${ }^{\star} P<0.05$ differences before and after VLCD within the same group. ${ }^{\dagger} P<0.05$ compared with lean subjects. ${ }^{\ddagger} P<0.01$ compared with lean subjects.

Total IGF-I levels were similar in all groups, and no significant change occurred during VLCD (Table 2).

IGFBP-2 levels were reduced in obese subjects compared with lean subjects. During caloric restriction, no increase in IGFBP-1 levels was observed in obese subjects, whereas an increase occurred in normal subjects and a trend towards an increase was present in obese subjects after weight loss (Table 2). IGFBP-2 levels increased during VLCD in obese subjects, whereas no change occurred during VLCD in lean and obese subjects after weight loss (Table 2).

ALS was similar in all groups and an increase occurred during VLCD in the obese subjects, whereas no significant decrease was present in the lean and obese subjects after weight loss (Table 2).

IGFBPs-3 and 4, and IGFBPs-1-3 proteolyse were similar in all groups and no significant changes occurred during VLCD, except for a decrease in IGFBP3 during VLCD in lean and obese subjects after weight loss (Table 2).

\section{HOMA and leptin}

Insulin sensitivity as assessed by HOMA-S was decreased in the obese subjects compared with the lean control subjects, whereas no difference was found in HOMA-S between the obese subjects after weight loss and the lean subjects (Table 2). The leptin levels were elevated in the obese subjects compared with the lean subjects, and no change occurred during caloric restriction in obese subjects.

\section{Discussion}

It has been hypothesized that a relatively increased amount of free IGF-I could be responsible for an enhanced feedback inhibition of $\mathrm{GH}$ secretion in obese subjects and a simple mechanism by which GH release is blunted in obesity during caloric restriction $(7,8)$ in contrast to lean subjects, where a GH increase is normally observed during caloric restriction $(8,20)$. The main findings in the present study are a decrease in circulating free IGF-I in obese subjects during a short-term hypocaloric diet in concert with unchanged 24-h GH release. It is possible that a relatively higher number of subjects would have potentially revealed additional changes in the explored parameters within groups during short-term VLCD due to decreased variability.

The majority of IGF-I is bound in a $150 \mathrm{kDa}$ complex, which consists of IGF-I, intact IGFBP-3, and ALS (21),

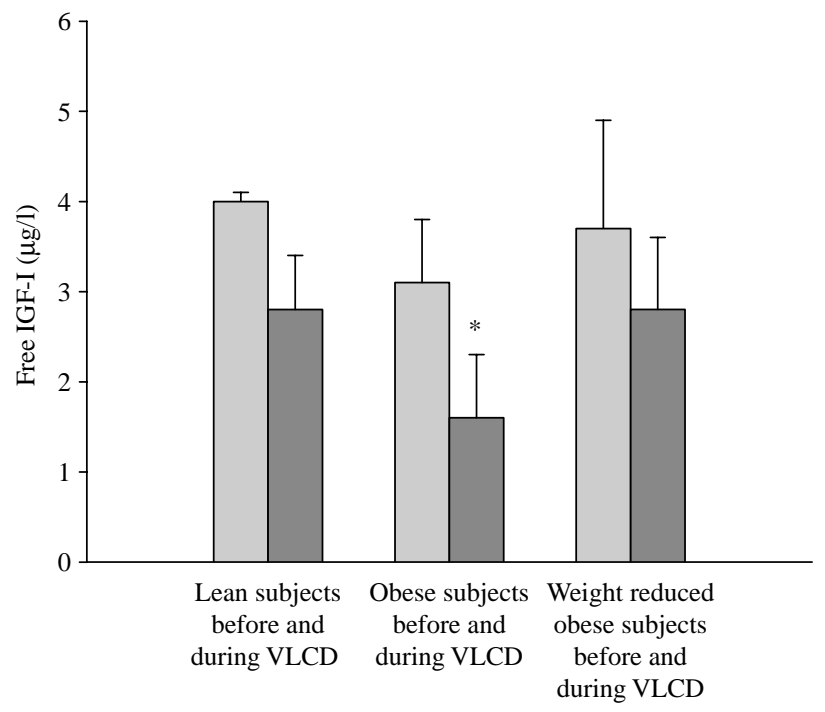

Figure 1 Free IGF-I levels. Columns represent (left to right) levels in lean subjects before and during a very low calorie diet (VLCD); levels in obese subjects before and during VLCD; and levels in obese subjects after weight loss before and during VLCD (mean \pm S.E.M.). ${ }^{\star} P<0.05$ for differences before and after VLCD within the same group. 


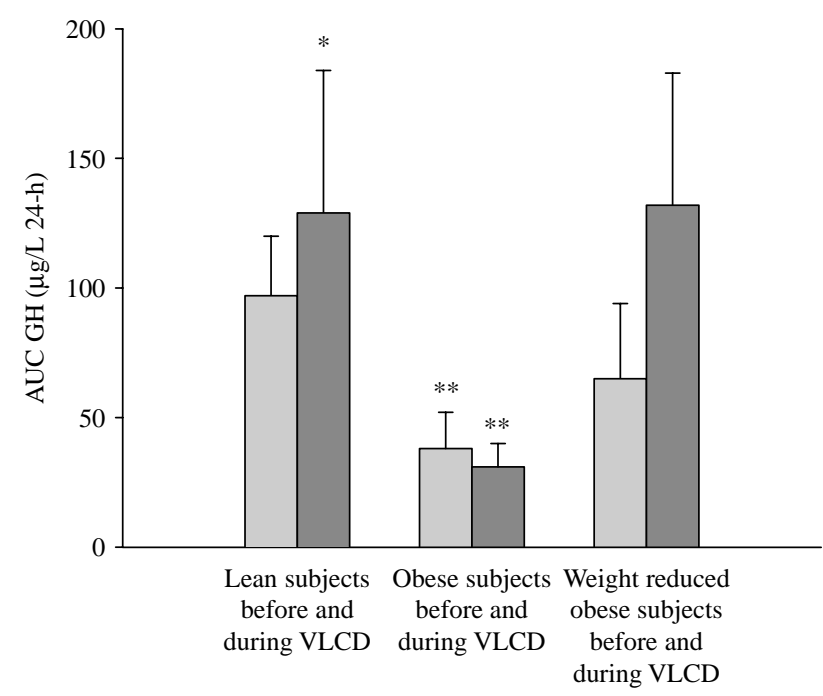

Figure 2 Twenty-four-hour growth hormone $(\mathrm{GH})$ area under the curve (AUC). Columns represent (left to right) levels in lean subjects before and during a very low calorie diet (VLCD); levels in obese subjects before and during VLCD; and levels in obese subjects after weight loss before and during VLCD (mean \pm s.E.M.). ${ }^{*} P<0.05$ differences before and after VLCD within the same group; ${ }^{\star \star} P<0.05$ compared with lean subjects.

and approximately $1 \%$ of IGF-I is free $(10,22)$. Thus, free IGF-I is dependent on the equilibrium between total IGF-I and total IGF-binding capacity in serum as well as IGFBP proteolysis, which is believed to be a general mechanism increasing IGF bioavailability, since IGFBP fractions have reduced affinity for IGF-I (23). In the present study, we found no increase in IGFBPs-1-3 proteolysis in obese subjects and no change in IGFBP-13 proteolysis during caloric restriction. Thus, IGFBP proteolysis cannot account for the observed differences and changes during caloric restriction observed with respect to free IGF-I and IGFBPs-1-3 levels.

We have previously reported 24-h GH release to be impaired in obese subjects in response to caloric restriction (7). However, the novel data reported now imply that circulating free IGF-I levels are not the inhibitory mechanism accountable for this blunted $\mathrm{GH}$ release in dieting obese subjects, since free IGF-I was found to decrease in concert with unchanged $\mathrm{GH}$ release. Another observation challenging the theory that $\mathrm{GH}$ hyposecretion in obesity merely reflects an enhanced negative feedback by high circulating free IGF-I is the report that rhIGF-I did not impose a significant inhibition of spontaneous GH secretion in obese subjects (24). In the present study, ALS, which regulates IGF-I by stabilizing the IGFBP-3-IGF-I binary complex was found to be increased in obese subjects during caloric restriction and thus might regulate and impact IGF bioavailability in dieting obese subjects.

IGFBPs-1-3 were intact during short-term caloric restriction, since no change in proteolytic activity was detected; further IGFBPs-1-3 determined by WLB, which supposedly shows intact IGFBPs, whereas immunoreactive levels of IGFBPs-1-3 may include inactive fragments of the binding proteins. IGFBP-2 is more abundant than IGFBP-1 in adults (25). In the present study, a significant increase occurred in IGFBP-2 in concert with a decrease in free IGF-I, which indicates that IGFBP-2 may have a role in regulating IGF-I bioavailability during short-term caloric restriction in obese subjects. Free IGF-II levels have previously been found to be elevated in obese subjects (26) and may impact IGFBP-4 proteolysis. Since IGFBP-4 functions mainly as a traditional binding protein, (27) it is important for the release of free IGF-I, however, in the present study, intact IGFBP-4 as determined by WLB was similar in the three groups and no change occurred during caloric restriction.

We and other researchers have previously shown that the molar ratio between total IGF-I and IGFBP-3, a rough estimate of free biologically active IGF-I, is decreased in obesity $(1,26)$, and normalized after dietinduced weight loss consistent with the transient GH-deficient state in obesity (1). The free IGF-I determination is not trivial due to methodological problems. In the present study, a commercially available assay for free IGF-I was used, which measures free IGF-I directly and it is argued that the free IGF-I fraction available to the antibody in this assay represents the free fraction that is available for the tissue (10). A high significant correlation between this assay and the free IGF-I levels determined by ultrafiltration method, a very laborious process (26), has been previously reported and they both correlate negatively with IGFBP-1 levels $(10,28)$. Free IGF-I has been previously reported to be relatively increased in one group of obese men and women (4) and two studies have reported increased free IGF-I levels in obese men $(29,30)$. However, observations on free IGF-I in obesity are not unanimous, since other studies have observed normal $(31,32)$ to low (6) free IGF-I levels in obese men and women. Free IGF-I levels have been reported unaltered during dietinduced weight loss (33). This unaltered, free IGF-I, after weight loss also challenges that $\mathrm{GH}$ hyposecretion in obesity merely reflects an enhanced negative feedback by high circulating free IGF-I, since GH secretion has been demonstrated to be returned to normal after weight loss in obesity (1-3).

Leptin has been suggested to be negatively related to GH secretion in obesity (34) and positively associated with hyperinsulinemia (2). During VLCD, we found a significant leptin decrease in lean subjects combined with an increase in IGFBP-1 and GH release, whereas no change occurred in leptin, IGFBP-1, or GH release in obese subjects. This could indicate that the increased leptin levels may be involved in the GH regulation during caloric restriction in obese subjects, whereas the increase in IGFBP-1, which has been previously shown to be inversely related to insulin levels may play a role in the increased GH release observed in lean subjects during 
VLCD. On the other hand, it has been shown that GH secretion is low in both obese subjects with hyperleptinemia and obese subjects with homo- and heterozygote mutations of the leptin gene (35), indicating that leptin does not mediate the blunted GH release seen in obesity. However, the persistent hyperleptinemia in response to a short-term VLCD may potentially be a beneficial adaptive response to severe obesity and induction of hyperleptinemia may be important for maintaining lost weight in weight-reduced subjects (36).

In summary, circulating free IGF-I seems normally to be controlled by total IGF-I and IGFBP-1, and the latter is inversely related to leptin. In the present study, free IGF-I levels decreased in concert with no significant changes in 24-h GH, IGFBP-1, or leptin during caloric restriction in obese subjects. We did not find any significant change in free IGF-I during caloric restriction, although levels tended to decrease in lean and obese subjects after weight loss. The GH-IGF axis in obesity is of increasing interest and may play a role in the development of obesity-related diseases especially seen in the light of recent reports, suggesting that low IGF-I levels are closely linked to the pathogenesis of type 2 diabetes and cardiovascular disease $(37,38)$.

We conclude that free (biologically active) IGF-I decreases with no concomitant change in 24-h GH-release after a short-term hypocaloric diet in obese subjects. Circulating free IGF-I per se cannot play a major role in the attenuated GH release during shortterm dieting in obesity.

\section{Acknowledgements}

We are grateful to Prof Allan Flyvbjerg for analyzing IGFBPs-1-4 and IGFBP proteolysis and Kirsten Jørgensen, Kirsten Nyborg, and Susanne Reimar for skilled technical assistance.

\section{References}

1 Rasmussen MH, Hvidberg A, Juul A, Main KM, Gotfredsen A, Skakkebaek NE \& Hilsted J. Massive weight loss restores 24-h growth hormone release profiles and serum insulin-like growth factor-I levels in obese subjects. Journal of Clinical Endocrinology and Metabolism $1995 \mathbf{8 0} 1407-1415$.

2 De Marinis L, Bianchi A, Mancini A, Gentiella R, Perrelli M, Giampietro A, Porcelli T, Tilaro L, Fusco A, Valle D \& Tacchino RM. Growth hormone secretion and leptin in morbid obesity before and after biliopancreatic diversion: relationships with insulin and body composition. Journal of Clinical Endocrinology and Metabolism 2004 89 174-180.

3 Engstrom BE, Burman P, Holdstock C, Öhrval M, Sundbom M \& Karlsson FA. Effects of gastric bypass on the GH/IGF-I axis in severe obesity - and a comparison with GH deficiency. European Journal of Endocrinology $2006 \mathbf{1 5 4} 53-59$.

4 Frystyk J, Skjaerbaek C, Vestbo E, Fisker A \& Ørskov H. Circulating levels of free insulin-like growth factors in obese subjects: the impact of type 2 diabetes. Diabetes Metabolism Research and Reviews $199915314-322$.
5 Nyomba BLG, Johnson M, Berard L \& Murphy LJ. Relationship between serum leptin and the insulin-like growth factor-I system in humans. Metabolism $1999 \mathbf{4 8} 840-844$.

6 Gomez JM, Maravall FJ, Gomez N, Navarro MA, Casamitjana R \& Soler J. The IGF-I system component concentrations that decrease with ageing are lower in obesity in relationship to body mass index and body fat. Growth Hormone and IGF Research 2004 14 91-96.

7 Rasmussen MH, Juul A, Kjems LL, Skakkebaek NE \& Hilsted J. Lack of stimulation of 24-h growth hormone release by hypocaloric diet in obesity. Journal of Clinical Endocrinology and Metabolism 199580 796-801.

8 Grottoli S, Gauna C, Tassone F, Aimaretti G, Corneli G, Wu Z, Strasburger CJ, Diequez C, Casanueva FF, Ghigo E \& Maccario M. Both fasting-induced leptin reduction and $\mathrm{GH}$ increase are blunted in Cushing's syndrome and in simple obesity. Clinical Endocrinology $200358220-228$.

9 Daughaday WH. Free insulin-like growth factor (IGF) in disorders of IGF binding protein 3 complex formation. Journal of Clinical Endocrinology and Metabolism 200489 3-5.

10 Juul A. Serum levels of insulin-like growth factor I and its binding proteins in health and disease. Growth Hormone and IGF Research 200313 113-170.

11 Bang P, Nygren J, Carlsson-Skwirut C, Thorell A \& Ljungqvist O. Postoperative induction of insulin like growth factor binding protein-3 proteolytic activity, relation to insulin and insulin sensitivity. Journal of Clinical Endocrinology and Metabolism 1998 83 2509-2515.

12 Soderberg S, Ahren B, Eliasson M, Dinesen B, Brismar K \& Olsson T. Circulating IGF binding protein-1 is inversely associated with leptin in non-obese men and obese postmenopausal women. European Journal of Endocrinology 2001144 283-290.

13 Liew CF, Wise SD, Yeo KP \& Lee KO. Insulin-like growth factor binding protein-1 is independently affected by ethnicity, insulin sensitivity, and leptin in healthy, glucose-tolerant young men. Journal of Clinical Endocrinology and Metabolism 200590 1483-1488.

14 Lamson G, Giudice LC \& Rosenfeld RG. A simple assay for proteolysis of IGFBP-3. Journal of Clinical Endocrinology and Metabolism 199172 1391-1393.

15 Hossenlopp P, Seurin B, Segovia-Quinnson B, Hardouin S \& Binoux M. Analysis of serum insulin-like growth factor binding proteins using western blotting: use of the method for titration of the binding proteins and competitive binding studies. Annals of Biochemistry 1986154 138-143.

16 Khosravi MJ, Diamandi A, Mistry J, Krishna RG \& Khare A. Acidlabile subunit of human insulin-like growth factor-binding protein complex: measurement, molecular, and clinical evaluation. Journal of Clinical Endocrinology and Metabolism $1997 \mathbf{8 2}$ 3944-3951.

17 Meriam GR \& Watcher KW. Algorithms for the study of episodic hormone secretion. American Journal of Physiology $1982 \mathbf{2 4 3}$ E310-E318.

18 Matthews DR, Hosker JP, Rudenski AS, Naylor BA, Treacher DF \& Turner RC. Homeostasis model assessment: insulin resistance and beta-cell function from fasting plasma glucose and insulin concentrations in man. Diabetologia 198528 412-419.

19 Levy JC, Matthews DR \& Hermans MP. Correct homeostasis model assessment (HOMA) evaluation uses the computer program. Diabetes Care 199821 2191-2192.

20 Ho KY, Veldhuis JD, Johnson MI, Furlanetto R, Evans WS, Alberti KG \& Thorner MO. Fasting enhances growth hormone secretion and amplifies the complex rhythms of growth hormone secretion in man. Journal of Clinical Investigation $1998 \mathbf{8 1}$ 968-975.

21 Jones JI \& Clemmons DR. Insulin-like growth factors and their binding proteins: biological actions. Endocrine Reviews 199516 3-34.

22 Frystyk J, Skjærbæk C, Dinesen B \& Ørskov H. Free insulin-like growth factors (IGF-I and IGF-II) in human serum. FEBS Letters 1994348 185-191. 
23 Fowlkes JL. Insulin-like growth factor binding protein proteolysis. Trends in Endocrinology and Metabolism 19978 299-306.

24 Maccario M, Tassone F, Gianotti L, Lanfranco F, Grottoli S, Arvat E, Muller EE \& Ghigo E. Effects of recombinant human insulin-like growth factor I administration on the growth hormone $(\mathrm{GH})$ response to GH-releasing hormone in obesity. Journal of Clinical Endocrinology and Metabolism 200186 167-171.

25 Clemmons DR, Snyder DK \& Busby WH. Variable controlling the secretion of insulin-like growth factor binding-2 in normal human subjects. Journal of Clinical Endocrinology and Metabolism 199173 727-878.

26 Frystyk J. Free insulin-like growth factors - measurements and relationships to growth hormone secretion and glucose homeostasis. Growth Hormone and IGF Research 200414 337-375.

27 Zhou R, Diehl D, Hoeflich A, Lahm H \& Wolf E. IGF-binding protein-4: biochemical characteristics and functional consequences. Journal of Endocrinology 20032 177-193.

28 Juul A, Flyvbjerg A, Frystyk J, Müller J \& Skakkebæk NE. Serum concentrations of free and total insulin-like growth factor-I, IGF binding proteins -1 and -3 and IGFBP-3 protease activity in boys with normal or precocious puberty. Clinical Endocrinology 199644 515-523.

29 Frystyk J, Vestbo E, Skjærbæk C, Mogensen CE \& Ørskov H. Free insulin-like growth factors in human obesity. Metabolism 199544 $37-44$.

30 Nam SY, Lee EJ, Kim KR, Cha BS, Song YD, Lim SK, Lee HC \& Huh KB. Effect of obesity on total and free insulin-like growth factor (IGF)-1, and their relationship to IGF-binding protein (BP)-1,IGFBP-2, IGFBP-3, insulin, and growth hormone. International Journal of Obesity and Related Metabolic Disorders 1997 21 355-359.

31 Nyomba BLG, Johnson M, Berard L \& Murphy LJ. Relationship between serum leptin and the insulin-like growth factor-I system in humans. Metabolism 199948 840-844.
32 Fernandez-Real JM, Pugeat M, Emptoz-Bonneton A \& Richart W. Study of the effect of changing glucose, insulin, and insulin-like growth factor levels on serum corticosteroid binding globulin in lean, obese and obese subjects with glucose intolerance. Metabolism 200150 1248-1252.

33 Espelund U, Bruun JM, Richelsen B, Flyvbjerg A \& Frystyk J. Proand mature IGF-II during diet- induced weight loss in obese subjects. European Journal of Endocrinology 2005153 861-869.

34 Fors H, Matsuoka H, Bosaeus I, Rosberg S, Albertsson-Wickland K \& Bjarnason R. Serum leptin levels correlate with growth hormone secretion and body fat in children. Journal of Clinical Endocrinology and Metabolism 199984 3586-3590.

35 Ozata M, Diequez C \& Casanueva FF. The inhibition of growth hormone secretion presented in obesity is not mediated by the high leptin levels, a study in human leptin deficiency patients. Journal of Clinical Endocrinology and Metabolism $2003 \mathbf{8 8}$ 312-316.

36 Rosenbaum M, Goldschmidt R, Bloomfield D, Magnano A, Weimar L, Heymsfield S, Gallagher D, Mayer L, Murphy E \& Leibel RL. Low-dose leptin reverses skeletal muscle, autonomic, and neuroendocrine adaptions to maintenance of reduced weight. Journal of Clinical Investigation 2005115 3579-3586.

37 Sandhu MS, Heald AH, Gibson JM, Cruickshank JK, Dunger DB \& Warreham NJ. Circulating concentrations of insulin-like growth factor-I and development of glucose intolerance: a prospective observational study. Lancet 2002359 1740-1745.

38 Juul A, Scheike T, Davidsen M, Gyllenborg J \& Jørgensen T. Low serum insulin-like growth factor I is associated with increased risk of ischemic heart disease. Circulation 2002106 939-944.

Received 21 April 2006

Accepted 6 July 2006 